Ana Souza

Language and faith encounters: bridging language-ethnicity and language-religion studies, International Journal of Multilingualism, vol. 13, no. 1 (2015)

DOI: $10.1080 / 14790718.2015 .1040023$

This version is available: https://radar.brookes.ac.uk/radar/items/230adca1-4e9a-4a76-8f32-fef1c9c11c1f/1/

Available on RADAR: 13.12.2016

Copyright (C) and Moral Rights are retained by the author(s) and/ or other copyright owners. A copy can be downloaded for personal non-commercial research or study, without prior permission or charge. This item cannot be reproduced or quoted extensively from without first obtaining permission in writing from the copyright holder(s). The content must not be changed in any way or sold commercially in any format or medium without the formal permission of the copyright holders.

This document is the author's accepted version. 


\section{Ana Souza}

There has been growing interest by British policy-makers in the importance of acknowledging the role of migrant children's background in their educational progress. Therefore, this article draws on studies of language-ethnicity and of language-religion to understand the linguistic and the religious heritage of four groups of Brazilian migrants in London. The discussions describe data collected for two studies. The first study was conducted in a Brazilian complementary school and the second, in three Brazilian faith settings. A new three-dimensional framework, the REL Triangle, is explained and applied to the two sets of data. It is argued that the REL triangle framework, which examines religion, ethnicity and language as intersecting aspects of identity, can help in the understanding of children's linguistic and cultural experiences in out-of-school contexts, and thus, allow new links to be developed between mainstream schools and migrant communities.

Keywords: Brazilian migrants, complementary schools, faith settings, language and ethnicity, language and religion

\section{Introduction}

There has been growing interest by British policy-makers in the role of migrant children's background in their educational progress (e.g. DCSF, 2009; DfES, 2003; DfES, 2002). This interest has been accompanied by the recommendation that issues of identity be explicitly dealt with for fostering citizenship (DfES, 2007). These recent developments provide the context within which to examine the results of two research projects involving Brazilian migrants, whose number have grown markedly in the UK in the last thirty years. The first project explored mothers' choices for taking their children to complementary schools (Souza, 2008), whilst the second project examined faith leaders' perspectives on the languages used in faith lessons with children (Souza, Kwapong and Woodham, 2012). This paper aims to examine religion, ethnicity and language as intersecting aspects of identity and to contribute to a better understanding of children's linguistic and cultural experiences out-of-school.

The role of complementary schools in language maintenance and identity formation has been acknowledged by studies with children of migrant heritage in the UK. Francis, Archer \& Mau (2010), for example, looked at the impact of complementary schools on the social and education identities of a group of Chinese students. They concluded that Chinese schools 
facilitated the students' links with China, its popular culture and also communication between generations. Creese, Bhatt, Bhojani \& Martin (2006), in examining the role of complementary schools in the identity formation of Gujarati young people, categorized the identity being promoted by the schools in three different positionings: heritage (links with Gujarati culture, history and language), learner (as a successful student in its own context and in relation to the mainstream school), and multicultural (in which an individual can move between cultures and languages in a flexible way). Multicultural identity was also salient in Prokopiou \& Cline's (2010) examination of how complementary schools influenced the construction of the cultural and the academic identities of young people of Greek and Pakistani ethnic background. These researchers claimed that the schools allowed the youngsters to negotiate differences and similarities within society and their communities, negotiations which enabled the construction of multiple identities based on dialogical oppositions rather than on conflicts.

Studies also point to the relevance of religion for the language maintenance, culture and sense of community of migrants. In studying the Lithuanian immigrants in Scotland, Dzialtuvaite (2006) claims that religion has provided this group with the only strong base to nurture their identity, culture and language. Being committed Catholics and unable to speak English, the first Lithuanians in Scotland bonded through religious services. The Catholic faith has been a strong bond among the elders; however, the church has seen its role weaken in the lives of the $4^{\text {th }}$ or $5^{\text {th }}$ generations. The youngsters' lack of contact with and interest in the Catholic Lithuanian community has led to the loss of their ancestors' language. Changes in linguistic, religious and ethnic identities have also been witnessed in groups which share the same geographical origins, as in Joseph's (2006) study of Lebanon. Although Arabic is the mother tongue of nearly the whole native-born Lebanese population, signalling religious differences through bilingualism in French was important at the beginning of this century. In 2000, Israeli occupation of South Lebanon ceased but the Syrians did not remove their troops from the country. This political change made Lebanon a Muslim controlled state, which led the Christian Lebanese to highlight their religious identities through their bilingualism in French. The link between language and religious identities are also referred to by Fernandez \& Clyne (2007). Their study on Sri Lankans in Melbourne presents indications that the Hindu families with a high degree of religious devoutness were more likely to maintain the Tamil language. Individuals' influence on language choices, as a consequence of their high levels of religious commitment, is also noted by Kouega (2008) in his study of Catholic services in Cameroon. 
In this article, the perspectives used to understand the relationship between language and ethnicity as well as between language and religion are discussed. These perspectives are then applied, respectively, to a study on Brazilian complementary schools and to a study on Brazilian faith settings in London. It is argued that both perspectives should be bridged under a single theoretical framework for a better understanding of children's religious, ethnic and linguistic experiences out of school.

\section{Language and ethnicity}

Fishman (1996) sees language and ethnicity as features of identity which mark and keep members linked to their groups. In his sociolinguistic perspective of the relationship between language and ethnicity, Fishman names three aspects of ethnicity: paternity, patrimony and phenomenology. Paternity can be defined as the inherited characteristics of an individual (being), patrimony as one's acquired characteristics (doing) and phenomenology as the way an individual feels in reference to both paternity and patrimony (knowing). 'Being, doing, and knowing' are the terms Fishman coined to refer to the three types of information which build ethnicity. But how can we access these types of information? Considering that the intergroup approach advocated by social psychology has contributed to an understanding of how minority groups relate to majority societies, Tajfel's (1978) theory of social identity is adopted in this article for exploring Fishman's aspects of ethnicity.

Tajfel's puts forward three types of minorities. There are those who wish to assimilate, those who are against assimilation, and those who adopt characteristics from both the majority and the minority groups. This classification can enable the understanding of what participants consider "was given" and "what was acquired" in the building of their ethnicity together with the meaning they attach to it. However, adopting the view that the positions one occupies in a social context (one's identities) are not fixed, it may be more effective to see types of identification as part of a continuum (Souza, 2008). This way, at the extremes and in opposing positions of the continuum are the minority members who reject involvement in the majority society - the "tourists" - and the ones who seek to assimilate into the majority group - the "natives". In between these two positions are those who are willing to adopt some of the characteristics from both the majority and the minority groups - the "cosmopolitans" (see Block, 2002).

\section{Language and religion}

One of the roles played by religion among migrant groups is that of state and civil society institutions, including the preservation of language (Freston, 2008). Therefore, I draw a 
parallel between Tajfel's (1978) types of minority groups discussed above and refer to the models presented by Clyne (1991) for the attitudes and practices in community languages in religious domains in Australia. Clyne proposes four models: (1) rapid assimilation, (2) transitional assimilation, (3) structural bi/multilingualism, and (4) pluralism. In the rapid and the transitional assimilation models, Australian churches provide services in community languages for recent migrants but a complete integration into an English-medium denomination is expected. The difference between these two models is in relation to the time required/allowed for the ethnic group to assimilate (Woods, 2004).

In the structural bi/multilingualism model, ethnic congregations conduct different community language or bilingual services within an English-dominated denomination. In the pluralism model, a close relationship between language and religion is maintained and the community language remains the language of the congregation, but concessions are made to the younger generation to prevent dropout. Both models seem to reflect the practices of minorities who value their characteristics but who are open to adopting some characteristics of the majority group. Interestingly, however, Clyne (1991) does not mention religious groups to whom their linguistic attachment has led to a separation from the Australian churches.

Moreover, in the same way that Tajfel's framework has been criticised for portraying a fixed view of identity, Woods (2004) felt the need to develop a two-dimensional framework for the relationship between language and religion and, thus, highlight the dynamic nature of their connection. In her concept of Language-Religion Ideology (LRI) Continuum, the relationship between language and religion is represented on a horizontal axis. The churches which believe that only a special language can be used with God, a strong link between language and religion, are placed on the left extreme of the continuum. The churches which attach a weak link between language and religion, and thus encourage the use of ordinary language for the building of a personal relationship with God, are placed on the right extreme of the continuum. The language practices of a congregation are represented on a vertical axis, where the use of English is on the top of the axis and the use of community language, on the bottom axis.

\section{Brazilians in the UK}

Brazilian migration to the UK only became significant in the $1980 \mathrm{~s}$, when the political and economic situation of Brazil led Brazilian nationals to migrate in search for work opportunities abroad. The UK is presently one of the top five countries in Europe with the largest number of Brazilian migrants (MRE, 2012). Consequently, Portuguese is the $11^{\text {th }}$ most 
spoken language in London mainstream schools (NALDIC, 2013) with almost 12,000 students in its boroughs (Eversley et al., 2010). In addition, there has been an increase in the number of secular and religious organizations set up to provide support to these migrants.

The variety of services offered through the use of the Portuguese language in London is large and includes services such as baby-sitting, beauty, building, financial, food, health, housing, legal, plumbing, transport and travel, among others. Another type of secular organizations that aim at supporting Brazilian migrants in London is complementary schooling. The first Brazilian complementary school on record started its activities at the end of the 1990s. Nowadays there are 13 of these schools in London (Souza and Barradas, 2014).

Brazilian migrants have also transplanted their religions to the UK. It is possible to attend religious services in Brazilian Portuguese in traditional Christian churches in eight Catholic parishes, at least 20 different Pentecostal (a sub-set of Protestants) denominations and 11 Kardecist groups (a Christian religion which combines spirit-mediumship and reincarnationist beliefs) across London. These numbers suggest that there might be a higher number of Brazilian children attending faith lessons than complementary schools.

\section{Study 1}

\subsection{Brazilian complementary school}

The research on language and identity was conducted in the South-west of London in a Brazilian complementary language school (CLS) which was created by a group of mothers who wanted their children to learn Portuguese and be exposed to Brazilian culture (Souza, 2008). At the time of the research, the school offered three different classes: stage 1 for children aged five to eight, focusing on the development of oral skills; stage 2 for children also aged five to eight who, having oral skills, would develop literacy skills; and stage 3 for children aged eight to twelve, to develop their literacy skills even further. There were about ten children in each of the levels offered by the school and which ran for two hours on Saturdays.

\subsection{Methodology}

The children's mothers were initially interviewed individually. The aim of these interviews was to draw a profile of the families in relation to the five factors that might influence their language attitudes and choices: (1) searching for social and economic success, (2) contact with the speech community, (3) attitudes towards the language and the culture, (4) different domains of language use and, (5) amount of contact with homeland. A schedule divided in four sections was designed for these semi-structured interviews: (1) language outside home, 
(2) language use in the home, (3) children, and (4) personal details. Language outside home, the first section, aimed at identifying the domains where the Portuguese language is be used in London. Language use in the home, section two, focused on the home domain use of language. It covered who speaks what language to whom in the family context. Children, the third section, elicited information about the children's age, their country of origin, linguistic knowledge and social networks as well as the cultural influences to which they were exposed. Personal Information, the fourth and last section, collected information about the parents and covered social status, contact with the speech community and, contact with homeland.

Since the mothers referred to identity as a factor which plays a major role in their choice of languages, their positioning in relation to language and identity were examined through a second set of qualitative interviews which were carried out in groups (Souza, 2008). These group interviews aimed at gaining an insider's view about the mothers' sense of ethnicity, their collective goals, their language attitudes and use. With this purpose in mind, 5 activities were designed. The first activity explored how the participants felt about relating physical appearance and geography to ethnic identity - a lead-in activity on the markers the participants considered relevant to their own ethnic identity. The second activity focused on the Brazilian ethnicity and aimed at eliciting markers of ethnicity such as culture, religion, dress, food, gesture, social status, ancestry amongst others that make the participants feel Brazilian. Activity three was used with the purpose of eliciting which of the intergroup goals (section 2) the participants adopted. Activity four focused on the mothers' expectations about their children in relation to their goals within the majority group, and thus, whether they considered it important for their children to be able to speak Portuguese and be exposed to Brazilian culture. The fifth and last activity looked specifically at the role of language in the construction of the ethnic identity of these participants.

\subsection{Mothers' perspectives on language and ethnicity}

The self-defined identity of the three mothers whose children attended the Brazilian CLS for the longest period of time has been reported elsewhere (Souza, 2008). This section focuses on the other six mothers interviewed and whose children attended the lessons for different periods of time. Their ways of self-identifying are examined in relation to the three types of inter-group interaction discussed above, i.e. "tourists", "native" and "early / expatriate cosmopolitans".

Carmélia ${ }^{1}$ is a mother whose self-identity tends towards the "tourist" type in the identity continuum in the sense that she does not to make an effort to be involved in British society, as she reports in her semi-structured interview (Souza, 2008). In spite of initially coming to 
England to study, Carmélia becomes a labour migrant. England to her now equals "home plus higher income" (Hannerz, 2000, p. 106) and she does not show any willingness to engage with the Other. Nevertheless, Carmélia's only involvement with the Brazilian community is through the CLS. It is through her conversations with her children that her 'Brazilianess' becomes part of her daily life. Carmélia also believes she expresses herself better in Portuguese, but her use of Portuguese with her children seems to be limited to giving instructions.

Three other mothers, namely Efigênia, Lindalva and Rogéria, self-identify towards the "expatriate cosmopolitan" type in the identity continuum. Efigênia is one of the few participants who reports making an effort to be involved with the Brazilian community in London. She consciously made this decision because she realised her son started to forget his Portuguese when he entered school. This change in his linguistic competence made Efigênia feel distant from her son. She believes that being able to speak a language enables her to understand the culture that goes with it. Hence her efforts to be involved in the Brazilian community and the CLS to offer her son more opportunities to learn her first language. Despite her efforts to be involved with the Brazilian community in London, Efigênia also considers it important to be part of British society and will not evade its influence. Efigênia believes it is possible to integrate and still be Brazilian. Lindalva and Rogéria report similar attitudes. Lindalva states that "[Integration means] being able to experience your daily life without attrition with the culture where one lives and preserving one's own culture"2. Rogéria, in turn, believes that "[i]t is impossible not to be influenced by the English culture, the way we should behave on a bus, at the cinema, in a restaurant".

Raimunda and Túlia, two mothers whose self-identity tend towards the "early cosmopolitan" type in the identity continuum, had different experiences in growing up in a foreign country and also in the way they relate to the Portuguese language. Raimunda grew up in a bilingual environment where she would speak Portuguese to her family and another language to other people in her social network. Therefore, she considers it to be important to raise her children with the same language pattern to assert her ethnicity as a Brazilian person. Raimunda feels that she has kept her Brazilian ethnicity as a result of her mother's efforts. She refers to the fact of being born in Brazil and speaking Portuguese as markers of her ethnicity, even though she does not consider them the most important ones. She refers to the way she sees the world as well as the way she behaves and her identification with the Brazilian culture as a legacy from her mother. Túlia also refers to the important role of her mother in helping her maintain links with Brazilian culture. 
My mother has a great influence in my life [...] She is the one who has led me to enrol my children in Portuguese lessons and the one who makes an effort to speak to them in Portuguese.

In the same way as Raimunda, Túlia also refers to behaviour when describing her 'Brazilianness', such as her experiences in Brazil during her childhood, whilst also noting the role of behaviour when relating to her family, such as the closeness between the family members and the family's presence in her daily life.

All the six Brazilian women examined here have in common the fact that they were born in Brazil and speak Portuguese as their first language. They are all in exogamous relationships and have children who they are raising in England. Nevertheless, the ways they describe and experience their ethnic identities vary, as expected by Hannerz (2000, p. 102):

There is now a world culture, but we had better make sure we understand what this means: not a replication of uniformity but an organization of diversity, an increasing interconnectedness of varied local cultures, as well as a development of cultures without a clear anchorage in any one territory. And to this interconnected diversity people can relate in different ways.

All in all, the research findings reported in this section suggest that Brazilian mothers connect their ethnic identity to the Brazilian Portuguese language. Therefore, they actively seek to expose their children to the use of Brazilian Portuguese, be it via their own use of the language, or their community ties, and still, their contact with their homeland and the complementary language school. Their sense of identity appears to influence their attitudes to their own mother tongue (Brazilian Portuguese) and the local language (British English), as well as the language through which they interact with their children. In broad terms, the links the mothers hold with their homeland and their speech community in London result from their needs of being in touch with their linguistic and cultural "roots". In this sense, they can be considered transnational migrants: individuals who establish themselves in a host country but continue to have links with their countries of origin (Levitt, 2003). Economically and educationally speaking, these families' social backgrounds differ (see Table 1 below). However, these families are linked to each other by the importance mothers give to the Brazilian Portuguese language in the construction of their identities and by their efforts in encouraging their children to speak this language.

"Table 1 see p. 21 below" 


\section{Study 2}

\subsection{Brazilian faith settings}

Besides the CLS, children of Brazilian heritage also have the opportunity to attend faith lessons in Portuguese in London, a transnational practice which keeps them connected to their heritage (Levitt, 2003). As mentioned earlier, religious services are held in Brazilian Portuguese in both Catholic and Protestant churches, as well as other religions which have developed a stronghold in Brazil, such as Kardecist meetings.

\subsubsection{The Catholics}

The first Brazilian Catholic priest arrived in London in 2002 under invitation from the British Diocese of the Catholic Church, as a result of the growing number of Brazilian Portuguese speakers attending their services. There are currently 3 priests who work in 8 parishes across London. The Brazilian Catholic Church offers catechism sessions once a week for about one and a half hours before their Sunday mass. Their main objective is to prepare the children for the sacraments of First Communion and Confirmation, with between 10 and 60 children attending each of these sessions in the different parishes. The Catholic faith lessons are delivered in Portuguese by volunteers who adopt catechism materials purchased in Brazil.

\subsubsection{The Pentecostals}

There are about 20 Brazilian Protestant churches in London, including Pentecostal ones. The pastors interviewed for this research arrived in London in 2005 which, as they explained, was in response to God's call to take their mission abroad. They offer four weekly services in their own premises. Their 'Sunday Schools' run in parallel to their services and aim at teaching Christian values. These sessions are attended by about 20 children and are based on materials obtained in the USA, being thus planned in English. There are 12 volunteers who take turns in delivering these sessions.

\subsubsection{The Kardecists}

The oldest Brazilian faith setting on record in London is the Kardecists, whose first group started their activities in 1992. There are presently 11 groups across London which run children's sessions in parallel to the adults' meetings. These sessions focus on the teachings of their doctrine and were initially delivered in Portuguese by volunteers who used materials brought from Brazil. It is possible however to witness a move towards the use of English with materials being produced locally by volunteers and being exchanged online with Brazilian 
groups in other English-speaking countries. The lessons are attended by an average of 10 children at each of their centres.

\subsection{Methodology}

The faith leaders of the three Brazilian ethnic churches (one Catholic parish, one Evangelical church and one Kardecist group) in this article were interviewed individually, except for the couple of pastors who were interviewed as a pair. The interviews were semi-structured and explored issues of religious, ethnic and linguistic identities as well as the historical background to the churches in the UK. The interviews aimed at understanding the language planning and policy being applied to the faith lessons designed for the children of the migrant families who attended their services. In addition to these interviews, lessons were observed, which allowed the negotiation of languages between teacher-children and children-children to be witnessed first-hand. In this article, however, only the data collected through the semistructured interviews are reported.

\subsection{Faith leaders' perspectives on language and religion}

As detailed in Souza et al. (2012), the Pentecostal male Pastor, for example, explains the incorporation of English into the services for the adults and into the faith lessons for the children as a way of preaching to reach all persons. The Catholic Priest's position in relation to the language use in the faith lessons stands in clear contrast to the one adopted by the Pentecostal male Pastor. Considering the parents to be more competent in Portuguese and expecting them to be their children's catechists, this is the language in which the children's sessions are delivered in the Catholic setting.

Both leaders, however, appear to be influenced by their theological beliefs in the language choices they make. This relationship between religious and language practices have been scrutinised by Woods (2004), who claims that an emphasis on a personal relationship with God may lead to the use of community languages for worshipping. However, some of the content of the interviews reported here indicate that exactly the opposite occurs. Not having a special language allocated for communicating with God has led the Pentecostal leaders to justify the replacement of their community languages by English. In case of the Catholic Priest, language choice was connected to another aspect of their theological beliefs: that of the role of parents as religious role models.

Although appearing to be more closely linked to language and ethnicity than to religion, the role of parents is also raised by the Kardecist Coordinator. 
[w] speak Portuguese [during the sessions], we present the tasks, for example, their homework is written in Portuguese. [The children] might not be able to read, you know, but the mother will, you see and it's a way in which they can be in touch with other Brazilian children, and it's an opportunity for them to talk [to each other in Portuguese]

In spite of being a strong advocate for the use of Portuguese in faith lessons, the Kardecist coordinator is aware of the constraints this language choice generates:

In Brazil, [...] all the children speak Portuguese [...] so there is that bunch of books. [If the children say] 'I don't like this book because it's very difficult', there are 20, 30 [different books] to choose from. Here we don't have this [choice]

The Catholic Priest also refers to problems in consequence of the children's linguistic competence. Some children are not literate in Portuguese and some newcomers are not literate in English. In other words, the issues of language choice do not seem to be easily resolved regarding children's faith lessons in ethnic churches. The lessons are affected by children's varied levels of language competence in the community language as well as competence in the majority language. This issue becomes even more complex in the case of the churches whose aims include attracting members from the majority society, such as the Pentecostal church (Souza et al., 2012).

This variation in children's linguistic competence in both English and Portuguese is largely due to the fact that Brazilian migration is a recent phenomenon in the UK, as noted above, and it is also on the rise. In other words, the arrival of new families with children whose language competence is higher (and solely) in Portuguese follows a constant pattern. So does the increase in the number of children of Brazilian heritage born and raised in England with high language competence in English. The complexity of the linguistic context in the faith settings can be seen in the leaders' concern with children's cultural links to their heritage, both in the case of the Kardecist group and the Catholic Church.

The Second Vatican Council of 1962-1965 introduced the use of the vernacular in place of Latin, which used to be considered a sacred language in Catholicism (Woods, 2006). That has allowed the Catholics to adopt a Language-Religion-Ideology (LRI) in which the use of ordinary language to communicate with God is encouraged and the use of community language is emphasised. As discussed in the language and religion section above, the Catholic 
Church in this article adopts a multilingual model, i.e. it conducts different community language services within an English dominated denomination (Clyne, 1991). In case of the Brazilian congregation specifically, Clyne's pluralism model - in which the community language remains the language of the congregation, but concessions may be made to younger generations - seems to apply. Albeit, the concessions are limited to allowing the children to sometimes express themselves and say prayers in English. As explained by the Catechism coordinator, this strategy is adopted to ensure the children's understanding, rather than preventing dropouts, as in Clyne's original model.

Following Woods' (2004) LRI continuum, the Pentecostal congregation can be placed towards the right extreme of the horizontal axis, where the link between language and religion is weak. In their case, different community language and bilingual services are offered and both Portuguese and English are used in their faith lessons. Nevertheless, the Pentecostal congregation does not totally fit Clyne's structural bi/multilingual model, as it does not function within an English dominated denomination. Neither does it fully fit into the pluralism model. A close relationship is maintained between language and religion, and concessions are made which incorporate other languages into the Pentecostal faith lessons and services. However, as illustrated above, these concessions are not focussed on catering for the language competence of the young generation who attend church. Their main concern is to attract locals to convert to their faith. Thus, I wonder if time will show whether, in fact, this Brazilian Pentecostal Church is adopting a transitional assimilation model.

There are some similarities between the Brazilian Pentecostals and the Kardecists. The attitudes and practices of the latter are not mentioned in Clyne's model, only in Tajfel's types of minorities: the one who is against assimilation. Their services were initially run by Brazilians for Brazilians in Portuguese only. By the late 90s, however, parallel sessions in English had been incorporated to cater for the local interest and some special events were offered with simultaneous translation into English. These practices fit Clyne's pluralism model, despite the fact that the use of English was focused on adults of different ethnolinguistic backgrounds, as in the case of the Pentecostal congregation. It was only at the beginning of 2010 that the Kardecist group started to use English for their children's faith lessons. Like the Pentecostal faith lessons, the Kardecist ones are planned in English and benefit from their transnational links. This seems to indicate that their attitudes and practices are no longer against assimilation. Considering that these lessons are the only ones always delivered in English, they seem to be adopting a model of transitional assimilation where attitudes and practices reflect a weak link between language and religion. 


\section{Bridging the studies}

Although the mothers in the first study totally ignored religion when discussing issues of language and ethnicity, the leaders' responses appear to indicate a link between their reasons for migrating, their religion and the language in which they deliver lessons to the children of Brazilian families in the UK. All in all, the two studies discussed above touched on issues of language and identity. More specifically, they examined how migration can affect the relationship between language and ethnicity as well as between language and religion within the context of Brazilian migrants in the UK. Both studies had, as a starting point, how the migrant groups related to the host society and thus drew on intergroup approaches. In the first case, Tajfel's three types of minorities were useful in understanding the importance of speaking Portuguese for the Brazilian mothers. In the second case, Clyne's four models of practices gave insights into the language choices made by faith leaders for the Brazilian churches they run in London. As discussed above, both approaches were expanded in order to reflect the fluid and multiple aspects of identity. Tajfel's types have been placed on a continuum (Souza, 2008) and Clyne's model has been replaced by Woods' (2004) notion of Language-Religion Ideology. The expansion of both approaches constitutes important contributions to a better understanding of language and identity issues in migration. In fact, Woods (2006) has already stressed that the place of language in ethnic churches is influenced by two sources: the cultural value system of an ethnic group and the culture of the religious denomination. Moreover, the interviews examined here indicate that integrating language, ethnicity and religion in one single framework would enhance the understanding of how they interact in the formation of one's identity.

In trying to bridge studies of language-ethnicity and language-religion, I then suggest the application of a three-dimensional framework which I refer to as the Religion-EthnicityLanguage (REL) Triangle. In this framework, each of the three aspects of identity is placed at one of the angles with a continuum moving inwards. A move towards the inner extremes of each of the continua represent weaker identity links with that aspect of their identity, whereas a move outwards means stronger links, as illustrated in Figure 1 below. 


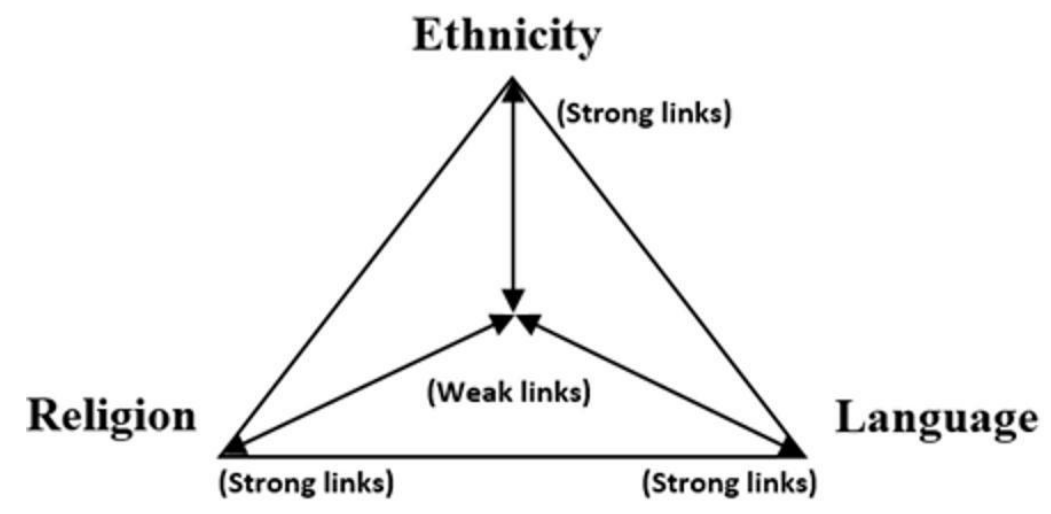

The language and ethnicity continuum used to interpret the self-identification of a group of Brazilian mothers in London enabled an appreciation that their identity positionings were not static, as shown above. The continuum was also a helpful device to represent the varied positions of the mothers in relation to each other. However, the issues which contributed to those positionings were not represented. In applying the REL Triangle framework to the mothers' perspectives on language and ethnicity, the relationship between religion, ethnicity and language becomes clearer. As illustrated in Figure 2, the mothers involved in the complementary language school (CLS) report their identities to have strong links with ethnicity and language, despite the varied ways in which they interact with the host society. Their lack of links with religion is also made apparent in this three-dimensional framework and explains the creation of a CLS as a secular setting which aims to disseminate the Portuguese language and Brazilian culture.

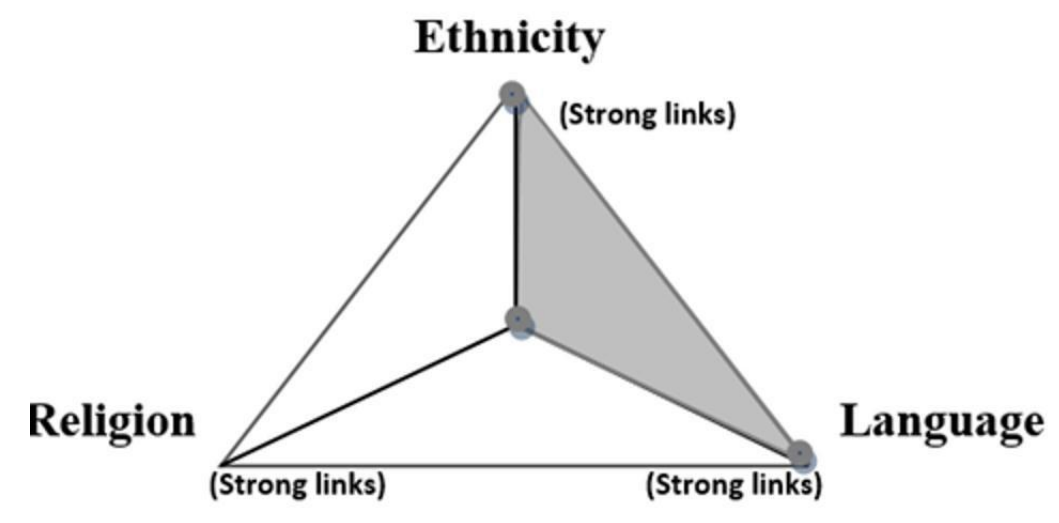

The strong links between language and ethnicity are also reported by the Catholic faith leaders. Applying the REL Triangle allows for a representation of these links as well as for the religious aspects of identity, as in Figure 3 below. This visual representation of the strong 
language-ethnicity links shows that religious, ethnic and linguistic identities go hand-in-hand in this setting and warrants the organization of Catholic faith lessons in Portuguese.

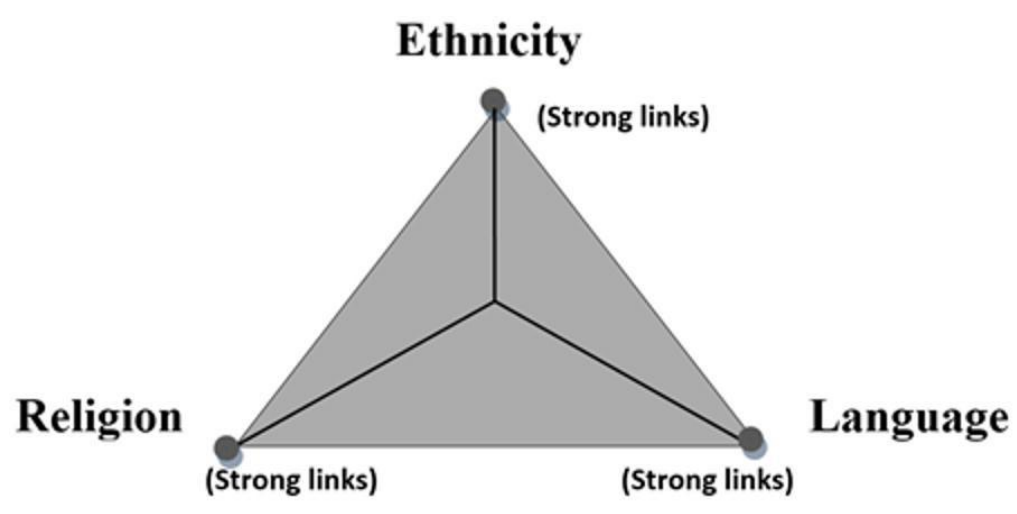

The strong links with religion are expected in all three faith settings being reported here. However, the settings differ in relation to how strongly they value their links with the other two aspects of identity in this three-dimensional framework. The Pentecostal leaders, for example, reported having loose links with ethnicity and language and placing a much higher value on the religious aspect of their identities, as in Figure 4.

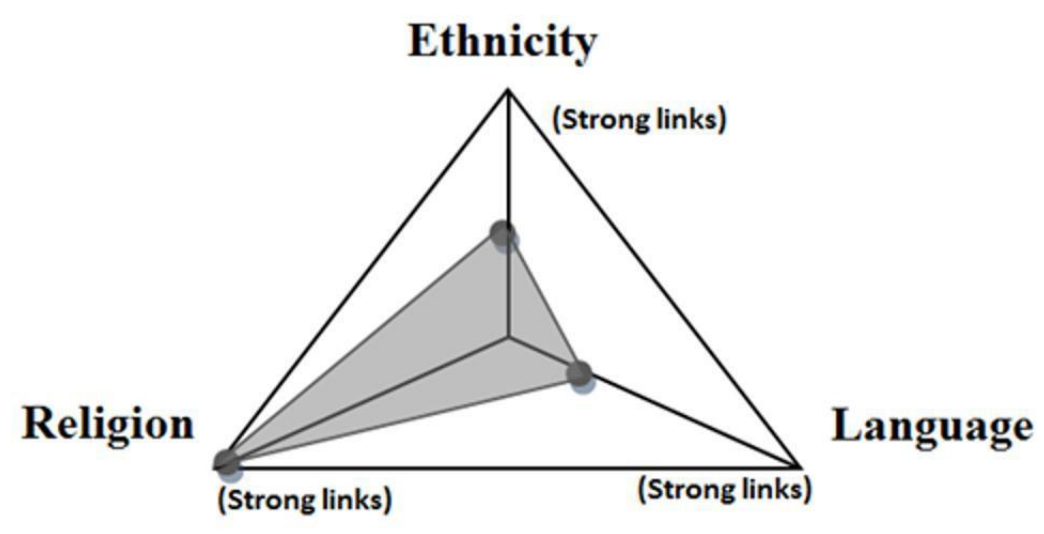

The Kardecists, who initially indicated being against assimilation, seem to be moving from holding strong links with language and ethnicity to a looser relationship to these aspects of their identities (Souza, 2014). This transitional stage is illustrated in Figure 5. 


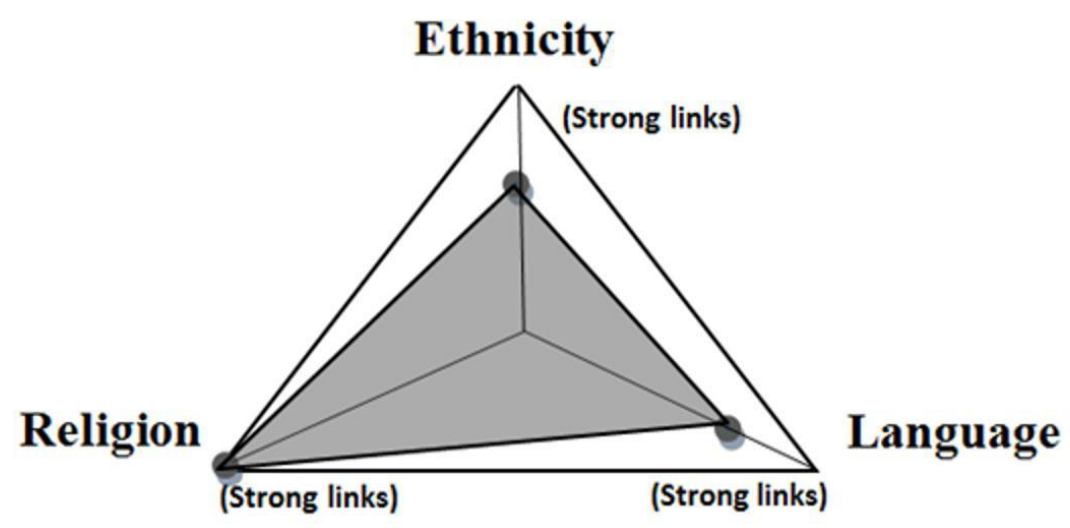

\section{Conclusion}

This article draws on research with 6 Brazilian mothers and compares it to a piece of research with 3 Brazilian faith settings - both in London. On examining these two cases, it became clear that research on language-ethnicity and language-religion lacked a common theoretical approach, and so a three-dimensional framework was developed: the Religion-EthnicityLanguage (REL) Triangle. This framework highlights the importance of each of these three aspects of identity, especially in the case of migrant communities, and thus, contributes to bridging the aforementioned gap.

The data presented suggest that, in migrating, the Brazilian mothers felt a need to keep cultural and linguistic links with their place of origin. This need has led them to consider ways in which their linguistic and cultural identities can be passed on to their children. This need is recognized by the Catholic priest who aims at supporting Brazilian migrants abroad and at enabling the children to be catechised by their parents. Therefore, his emphasis on the use of Portuguese. The Pentecostal church pastors migrated with the intention of converting the locals into their religion. Consequently, they put great emphasis on the use of English. The Kardecists initially held activities to Brazilian migrants in Portuguese. A movement however has been noticed in relation to adopting English in order to spread their faith to the local community.

The REL Triangle is a tentative framework which needs refining, especially in relation to how its three aspects (religion, ethnicity and language) can be measured. The Astley-Francis Scale of Attitude toward Theistic Belief (Astley et al, 2012) is being considered as a test which could be adapted for use along with the REL Triangle. Nevertheless, the application of the REL Triangle in its present stage has indicated that explorations of the value of each of these aspects could help to obtain a better understanding of the perspectives of all involved in the different settings: (faith) leaders, parents, (faith) teachers and children. In this way more 
can be known about children's linguistic and cultural experiences out-of-school. With a view to supporting children's emotional well-being, this knowledge could allow new links to be developed between mainstream schools and migrant communities, a rich area to be explored in further studies. This knowledge would also contribute to the embodiment of pupils' cultural inheritance in the school curriculum, as recommended by the Schools Whitepaper (DfE 2010). It is important to note, however, that this document does not explicitly refer to religion and appears to favour the culture of the elite. Therefore, the impact of this document on policies is still to be seen, especially in relation to the migrant groups in the UK.

\section{Acknowledgements}

The author thanks the women and the faith leaders who have kindly spent time to share their feelings, opinions and experiences as part of the two projects reported in this article. The author also thanks Yara Evans for commenting on an early draft of this article and Yvert de Souza for proofreading its final version.

\section{Notes}

1. All the names in this article are pseudonyms.

2. All quotes in italics were originally in Portuguese.

\section{References}

Astley, J., Francis, L., \& Robbins, M. (2012). Assessing attitude towards religion: The Astley-Francis Scale of Attitude toward Theistic Belief. British Journal of Religious Education, 34, 183-193.

Block, D. (2002). Destabilized identities and cosmopolitanism across language and cultural borders: two case studies. Hong Kong Journal of Applied Linguistics 7(2), 1-11.

Clyne, M. (1991). Community Languages: The Australian Experience. Cambridge: Cambridge University Press.

Creese, A., Bhatt, A., Bhojani, N. \& Martin, P. (2006). Multicultural, Heritage and Learner Identities in Complementary Schools. Language and Education 20(1), 23-43.

DCSF. (2009). Your child, your schools, our future: building a 21st century schools system. London: HMSO.

DfE. (2010). The Importance of Teaching - The Schools Whitepaper. London: HMSO.

DfES. (2002). National Languages Strategy. London: HMSO.

DfES. (2003). Aiming High. Raising the Achievement of Minority Ethnic Pupils. London: HMSO. 
DfES. (2007). Curriculum review: diversity and citizenship. London: HMSO.

Dzialtuvaite, J. (2006). The role of religion in language choice and identity among Lithuanian immigrants in Scotland. In T. Omoniyi \& J. Fishman (Eds.), Explorations in the Sociology of Language and Religion (pp. 79-85). Amsterdam: John Benjamins.

Eversley, J., Mehmedbegović, D., Sanderson, A., Tinsley, T., vonAhn, M. \& Wiggins, R. (2010). Language Capital - mapping the languages of London's school children. London: CILT.

Fernandez, S. \& Clyne, M. (2007). Tamil in Melbourne. Journal of Multilingual and Multicultural Development 28(3), 169-187. doi: 10.2167/jmmd488.0

Fishman, J. (1996). Ethnicity as Being, Doing and Knowing. In J. Hutchinson \& A. Smith (Eds.), Ethnicity (pp. 63-69). Oxford: Oxford University Press.

Francis, B., Archer, L. \& Mau, A. (2010). Chinese complementary school pupils' social and educational subjectivities. In V. Lytra \& P. Martin (Eds.), Sites of Multilingualism complementary schools in Britain today (pp. 85-96). Stoke-on-Trent: Trentham.

Freston, P. (2008). The Religious Field among Brazilians in the United States. In C. JouëtPastré \& L. J. Braga (Eds.), Becoming Brazuca, Brazilian Immigration to the United States, (pp. 255-268). Cambridge, MA: Harvard University Press.

Hannerz, U. (2000/1996). Transnational Connections. London: Routledge.

Joseph, J. (2006). The shifting role of languages in Lebanese Christian and Muslim identities. In T. Ominiyi \& J. Fishman (Eds.), Explorations in the Sociology of Language and Religion (pp. 165-179). Amsterdam: John Benjamins.

Kouega, J. (2008) Language, Religion and Cosmopolitanism: Language Use in the Catholic Church in Yaounde, Cameroon. International Journal of Multilingualism, 5(2), 140-153. doi: $10.1080 / 14790710802152347$

Levitt, P. (2003). "You Know, Abraham Was Really the First Immigrant": Religion and Transnational Migration. International Migrant Review, 37(3), 847-873.

MRE. (2012). Brasileiros no mundo [Brazilians in the World]. Retrieved from http://www.brasileirosnomundo.itamaraty.gov.br/a-comunidade/estimativaspopulacionais-das-comunidades/APENDICE\%20Diplomacia\%20Consular\%20$\% 20$ Brasileiros $\% 20$ no\%20Mundo.pdf

NALDIC (2013) Languages in School. Retrieved from www.naldic.org.uk/research-andinformation/eal-statistics/lang.xlsx

Prokopiou, E., \& Cline, T. (2010). Constructing cultural and academic identities in community schools: a socio-cultural and dialogical approach. In V. Lytra \& P. Martin (Eds.), Sites of Multilingualism - complementary schools in Britain today (pp. 71-83). Stoke-on-Trent: Trentham. 
Souza, A. (2008) How Linguistic and Cultural Identities are Affected by Migration. Language Issues 19(1), 36-42.

Souza, A. (2014) Technology and language planning: the case of a Brazilian faith setting in London. In D. Mallows (Ed.), Language issues in migration and integration: perspectives from teachers and learners (pp. 135-150), London: British Council ESOL Nexus.

Souza, A. \& Barradas, O. (2014) Português como Língua de Herança: Políticas Linguísticas na Inglaterra. Revista SIPLE $6(1)$ Retrieved from: http://www.siple.org.br/index.php?option=com_content\&view=article\&id=297:portuguescomo-lingua-de-heranca-politicas-linguisticas-na-inglaterra\&catid=69:edicao-

$\underline{6 \& \text { Itemid }=112}$

Souza, A., Kwapong, A. \& Woodham, M. (2012) Pentecostal and Catholic churches in London - the role of ideologies in the language planning of faith lessons. Current Issues in Language Planning 13(2), 105-120. doi:10.1080/14664208.2012.678977

Tajfel, H. (1978). The Social Psychology of Minorities (Minority Rights Group Report No 38). London: Minority Rights Group.

Woods, A. (2004). Medium or Message? - Language and Faith in Ethnic Churches, Clevedon: Multilingual Matters.

Woods, A. (2006). The role of language in some ethnic churches in Melbourne. In T. Ominiyi \& J. Fishman (Eds.) (pp. 197-212). 


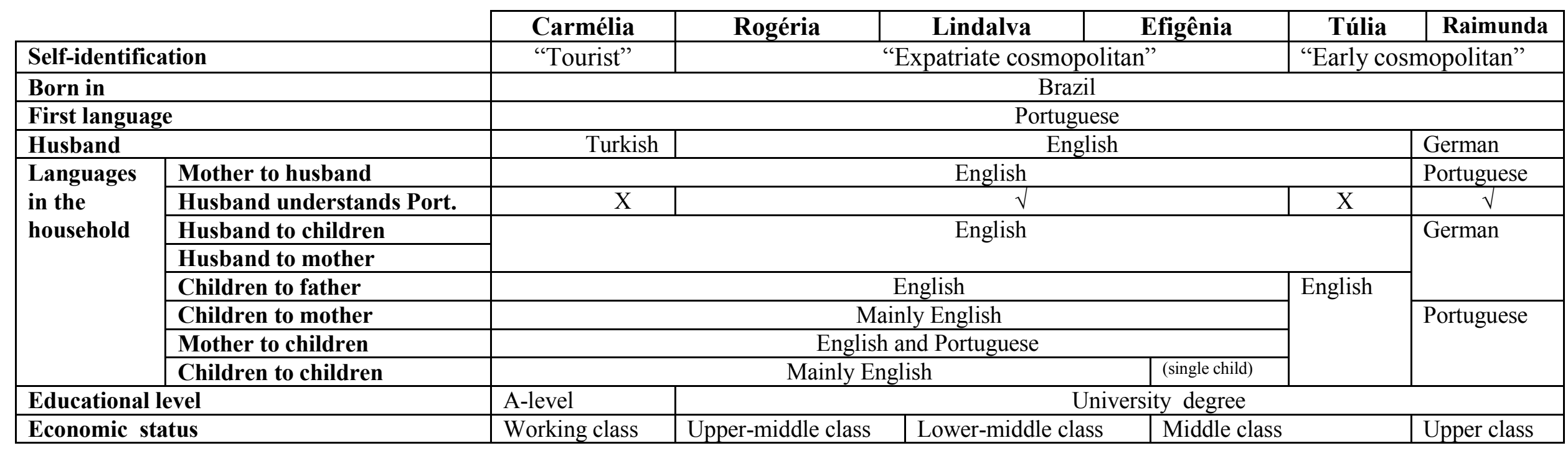

Table 1 - Mothers' Profiles 